\title{
Constraining the brachial plexus does not compromise regional control in oropharyngeal carcinoma
}

\author{
Mutter W Robert ${ }^{1 * \dagger}$, Benjamin H Lok ${ }^{2 \dagger}$, Pinaki R Dutta ${ }^{2}$, Nadeem Riaz ${ }^{2}$, Jeremy Setton ${ }^{2}$, Sean L Berry ${ }^{3}$, \\ Anuj Goenka ${ }^{2}$, Zhigang Zhang ${ }^{4}$, Shyam S Rao', Suzanne L Wolden ${ }^{1}$ and Nancy Y Lee ${ }^{1}$
}

\begin{abstract}
Background: Accumulating evidence suggests that brachial plexopathy following head and neck cancer radiotherapy may be underreported and that this toxicity is associated with a dose-response. Our purpose was to determine whether the dose to the brachial plexus (BP) can be constrained, without compromising regional control.

Methods: The radiation plans of 324 patients with oropharyngeal carcinoma (OPC) treated with intensity-modulated radiation therapy (IMRT) were reviewed. We identified 42 patients (13\%) with gross nodal disease $<1 \mathrm{~cm}$ from the BP. Normal tissue constraints included a maximum dose of $66 \mathrm{~Gy}$ and a $\mathrm{D}_{05}$ of $60 \mathrm{~Gy}$ for the BP. These criteria took precedence over planning target volume (PTV) coverage of nodal disease near the BP.

Results: There was only one regional failure in the vicinity of the BP, salvaged with neck dissection (ND) and regional re-irradiation. There have been no reported episodes of brachial plexopathy to date.

Conclusions: In combined-modality therapy, including ND as salvage, regional control did not appear to be compromised by constraining the dose to the BP. This approach may improve the therapeutic ratio by reducing the long-term risk of brachial plexopathy.
\end{abstract}

Keywords: Brachial plexopathy, Intensity-modulated radiation therapy, Oropharyngeal carcinoma, Cisplatin, Cetuximab

\section{Background}

Brachial plexopathy is a potentially painful and debilitating complication of radiotherapy, characterized by sensory changes and motor deficits [1]. The time to the appearance of symptoms may vary significantly. Recent modern studies have reported median times to onset of symptoms ranging from 6.5 months to 4 years from the completion of radiotherapy and ranges of 1.4 months to 26 years $[2,3]$. Once they develop, there may be a gradual evolution of symptoms or a more rapid progression with time, which may on occasion culminate in complete loss of function of the affected arm [1,4]. Treatment options for these patients remain inadequate, and prognosis is poor. Brachial plexopathy has been

\footnotetext{
*Correspondence: mutter.robert@mayo.edu

${ }^{\dagger}$ Equal contributors

'Department of Radiation Oncology, Mayo Clinic, 200 First Street SW,

Rochester, Minnesota 55905, USA

Full list of author information is available at the end of the article
}

associated with greater cumulative radiation dose to the brachial plexus (BP), radiotherapy fraction size, maximum dose, as well as the addition of chemotherapy and neck dissection [1,2,4-6]. One group recently used a validated symptom questionnaire in order to screen a large head-and-neck cancer population who had undergone radiation therapy. Their goal was to identify predictors of neuropathic symptoms thought to be related to brachial plexopathy. Interestingly, $12 \%$ of patients reported neuropathic symptoms, and there was a clear dose-response relationship [6]. They concluded that dose to the brachial plexus should be limited when possible. Suggested BP normal tissue constraints on recent IMRT head and neck protocols are shown in Table 1.

Intensity-modulated radiotherapy (IMRT) allows for accurate targeting of disease while minimizing dose to surrounding critical normal structures and has become the standard treatment technique for the management of oropharyngeal carcinoma and many other head and

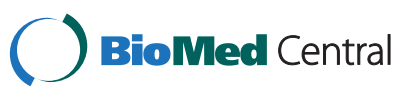




$\begin{aligned} & \text { Table } 1 \text { Brachial plexus constraints on recent Radiation } \\
& \text { Therapy Oncology Group intensity-modulated } \\
& \text { radiotherapy head and neck cancer protocols }\end{aligned}$
\begin{tabular}{ll}
\hline Protocol & Brachial plexus constraint \\
\hline RTOG 0022 & None specified \\
RTOG 0025 & None specified \\
RTOG 0522 & Dmax $\leq 60$ Gy \\
RTOG 0615 & Dmax $\leq 66$ Gy* \\
RTOG 0619 & Dmax $\leq 66$ Gy, D05 $\leq 60$ Gy \\
RTOG 0912 & Dmax $\leq 66$ Gy to point source at least $0.03 \mathrm{~cm}^{3 * *}$ \\
RTOG 1008 & Dmax $<60$ Gy if no involved low neck nodes; $<66$ Gy \\
& if low neck involved
\end{tabular}

RTOG 1016 None specified.

*The treating radiation oncologist has the option of prescribing an intermediate dose of $63 \mathrm{~Gy}_{1} \mathrm{PTV}_{63}$ in the lower neck close to the brachial plexus.

**Suggested dose limit that should not compromise tumor coverage.

neck cancers. When locally advanced head and neck cancers are treated definitively with IMRT, the planning target volume (PTV) encompassing gross primary and nodal disease is generally prescribed a dose of $70 \mathrm{~Gy}$. If lymphadenopathy is present in proximity of the BP, however, it is often difficult to constrain the dose to the $\mathrm{BP}$ to meet normal tissue tolerance guidelines without at least some compromise of PTV coverage.

In the context of multi-modality therapy for head and neck cancers, including chemotherapy and neck dissection as salvage, IMRT treatment-planning guidelines were adopted at Memorial Sloan-Kettering Cancer Center in 2005 with the goal of reducing the risk of brachial plexopathy. These allowed for less than 100\% coverage of the PTV in the low neck with the 70Gy isodose line to ensure adherence to BP normal tissue constraints of a maximum point dose (Dmax) of 65-66 Gy and a dose received by $5 \%$ of the tissue $\left(D_{05}\right)$ of $60 \mathrm{~Gy}$. We recently reviewed the treatment plans of patients with squamous cell carcinoma of the oropharynx who underwent IMRT at our center. Our purpose was to determine whether these brachial plexus constraints impacted regional control.

\section{Materials and methods}

\section{Patients/evaluation}

Between January 2005 and April 2009, 324 patients with histologically confirmed squamous cell carcinoma of the oropharynx underwent definitive IMRT at our center. From this group of 324 patients definitively treated with IMRT after Institutional Review Board Approval we identified 42 patients (13\%) who had clinically or radiographically positive gross nodal disease $<1 \mathrm{~cm}$ from the BP. These 42 patients were the subjects of this study. January 2005 was chosen as a cut-off because it was at that time that we began contouring and constraining the BP for all patients treated with IMRT for head and neck cancer at our institution. This retrospective analysis was approved by our Institutional Review Board.

Pretreatment evaluation included a complete history and physical examination, flexible fiberoptic endoscopic examination, complete blood counts, liver function tests, chest X-ray, and dental evaluation, as well as magnetic resonance imaging and/or computed tomography (CT) scans of the head-and-neck region. CT scans of the chest and abdomen, and positron emission tomography (PET) scans were also obtained for most patients before the start of treatment.

\section{Treatment}

Our treatment-planning techniques have previously been described [7-9]. To account for setup error, the PTV was defined to encompass the gross primary and neck disease plus margin $(0.3-0.5 \mathrm{~cm})$, the $\mathrm{PTV}_{59.4}$ was defined as the high-risk subclinical disease plus margin (0.3-0.5 cm), and the PTV P4 $_{54}$ was defined as the low-risk subclinical disease plus margin $(0.3 \mathrm{~cm})$. We frequently use a split-field technique for cancers of the oropharynx when lymph nodes are not situated near the larynx, in order to reduce the dose to that structure. All 42 patients reported here, however, had clinically a dosepainting whole-neck IMRT technique [8].

Platinum-based chemotherapy was administered to 31 of the 42 patients (74\%). Concurrent single-agent cisplatin was the primary choice of chemotherapeutic agent, consisting of a planned two to three cycles $\left(100 \mathrm{mg} / \mathrm{m}^{2}\right)$ of cisplatin on days 1,22 , and 43 . Eleven (26\%) received cetuximab. Routine planned neck dissections were not undertaken. Rather, a PET/CT scan was typically performed 3 months after the completion of radiotherapy and neck dissection was reserved for patients with less than a complete response on imaging or clinical examination. Location of dissected lymph nodes was determined prospectively based on pathology reports.

\section{Constraining the brachial plexus}

The BP was contoured for all patients prior to treatment using a modified version of the Radiation Therapy Oncology Group guidelines, with the most superior extent of the structure at the level of the cricoid cartilage. Normal tissue constraints adhered to included a Dmax of 66 Gy and a $D_{05}$ of 60 Gy for the BP. Gross tumor volume coverage was generally prioritized. However, the BP dose volume criteria routinely took precedence over PTV coverage near the BP. In order to study the dosimetric impact of the BP constraints on PTV coverage, we defined $\mathrm{PTV}_{\mathrm{BP} 70}$ as the portion of the PTV prescribed $70 \mathrm{~Gy}$ from $6 \mathrm{~mm}$ superior to $6 \mathrm{~mm}$ inferior of the ipsilateral BP. The $6 \mathrm{~mm}$ distance was chosen because PTV coverage outside of this range would not be expected to be significantly 
impacted by the BP avoidance structure. Any recurrences occurring within or adjacent to the $\mathrm{PTV}_{\mathrm{BP70}}$ were presumed to have been potentially caused by the BP dose constraint. Dose volume histograms were created for all 42 patients and dose volume parameters for the BP and PTV $_{\text {BP70 }}$ were analyzed. Thirteen patients had bilateral gross nodal disease within $1 \mathrm{~cm}$ of the BP. The dose volume parameters for both the $\mathrm{BP}$ and $\mathrm{PTV} \mathrm{V}_{\mathrm{BP} 70}$ were analyzed independently in these patients.

\section{Follow-up}

Patients were evaluated weekly during RT. After the completion of radiation, patients were evaluated every 2-3 months for the first 2 years and every 4-6 months thereafter. All All patients, including those who developed distant metastases, continued to be monitored closely with regular physical exams, flexible fiberoptic endoscopy, and radiographical studies to assess for locoregional recurrence and symptoms of brachial plexopathy. Human papillomavirus (HPV) status was unavailable for patients on this study, but smoking status, including median number of pack-years, is reported.

\section{Statistical methods}

The cumulative incidence function was used to describe local recurrence, regional failure, and distant metastasis. Death without recurrence was regarded as a competing risk [10]. The time to recurrence was defined as the time (in months) elapsed from the start of radiation to the date of recurrence, death, or last follow-up. The KaplanMeier method was used to describe overall survival [11].

\section{Results}

Characteristics of the 42 patients are summarized in Table 2. The primary site was located in the base of tongue in $69 \%$ and in the tonsil in $31 \%$. Seventy-one percent of patients were greater than 55 years old. Patients in this study had low neck disease involvement in proximity of the BP, and therefore relatively advanced-stage disease compared to all patients presenting with oropharyngeal carcinoma [12,13]. Forty-one of 42 patients (97.6\%) were AJCC stage IV, including 6 patients (14.3\%) with lymph nodes greater than $6 \mathrm{~cm}$ in maximum diameter (N3).

Dose volume parameters of the $\mathrm{BP}$ and $\mathrm{PTV}_{\mathrm{BP} 70}$ for the entire cohort are displayed in Table 3. For the $\mathrm{PTV}_{\mathrm{BP} 70}$, the median D95 was $66.7 \mathrm{~Gy}$ and the median minimum point dose (Dmin) was 58.7 Gy. For the BP, the median Dmax was 63.4 Gy and the median D05 was 59.1 Gy. Just one patient in this study had both a BP Dmax and $\mathrm{D}_{05}$ greater than 65 Gy and 60 Gy, respectively. The radiation plans with corresponding isodose lines for two representative patients are displayed in Figure 1A and Figure 1B.

\section{Treatment outcomes}

The median follow-up time was 35 months (range, 1-69). Of the 42 patients, 8 underwent post-RT neck dissection due to clinical or radiograph evidence of residual disease following RT. For the $\mathrm{PTV}_{\mathrm{BP} 70}$ of these 8 patients, the median D95 was 67.4 Gy and the median Dmin was 59.4 Gy. Histologic evidence of residual cancer was identified in 4 of these 8 patients. In one of the 4 patients, a single level 2 node contained viable tumor. In three patients, multiple lymph nodes from the upper as well as the lower neck contained viable tumor.

To date, there have been six regional recurrences. The cumulative incidence of regional failure was $14 \%$ (95\% CI 0.04- 0.25, Figure 2). For the PTV $\mathrm{BP}_{\mathrm{BP0}}$ of these 6 patients, the median D95 was 67.96 Gy and the median Dmin was 59.2 Gy, demonstrating slightly greater PTV coverage than the median for the entire cohort. Review of pre- and posttreatment imaging, operative notes, and pathology reports demonstrated that just one isolated regional failure occurred close to the $\mathrm{PTV}_{\mathrm{BP} 70}$ This patient presented with a $>10 \mathrm{~cm}$ level 3 node invading the skin. Following chemoradiation, there was residual hypermetabolic activity in the periphery of the mass, and a planned neck dissection was performed. Pathology demonstrated a cystic nodule of squamous cell carcinoma that was mostly necrotic ( $<1 \%$ viable tumor cells present). All 28 other excised lymph nodes were negative. There was concern at surgery for possible unresectable residual disease at the carotid bulb which in this patient was above the brachial plexus at the level of the 4th cervical vertebral body. Therefore regional re-irradiation was administered postoperatively. The patient developed evidence of distant metastases 2 months following the completion of reirradiation and eventually succumbed from his disease with disease locoregionally controlled. The $\mathrm{D}_{95}$ and Dmin of the $\mathrm{PTV}_{\mathrm{BP70}}$ for that patient were 62.3 and $51.6 \mathrm{~Gy}$, respectively. The other 5 regional failures in the study included: Patient 1) A new contralateral out-of-field level 5 nodal neck failure in a previously node-negative hemineck; Patient 2) A new ipsilateral high neck lymph node at level II; Patients 3 and 4) Local recurrences with an adjacent regional node in the high level II neck; 5) Local recurrence and regional disease in level II and level IV.

The median number of pack-years smoked for the 6 patients with regional failures was 13 . One of the six patients was a never smoker, and 4 had a greater than 10 pack-year smoking history. Due to the small number of events, we could not determine whether smoking status was associated with a higher likelihood of regional recurrence.

The cumulative incidence of local recurrence and distant metastasis were $10 \%$ (95\% confidence interval [CI] 0.005-0.19, Figure 3A), and 29\% (95\% CI 0.15-0.43, Figure 3B), respectively. The 3-year Kaplan-Meier estimated 
Table 2 Patient characteristics

\begin{tabular}{|c|c|c|}
\hline Characteristic & Number (\%) & Carboplatin/5-FU \\
\hline Sex & & Carboplatin/paclitaxel \\
\hline Male & $39(92.9 \%)$ & $11(26.2 \%)$ \\
\hline Female & $3(7.1 \%)$ & Cisplatin/bevacizumab \\
\hline Age & & Induction + concurrent \\
\hline$\leq 55$ & $12(28.6 \%)$ & \multirow{5}{*}{$\begin{array}{l}\text { Abbreviations: AJCC American Joint Committee on Cancer, 5-FU 5-fluorouracil, } \\
\text { KPS Karnofsky performance status. } \\
\text { overall survival probability was } 76 \% \text { (95\% CI 0.64-0.90, } \\
\text { Figure 3C). There have been no reported episodes of } \\
\text { brachial plexopathy to date. }\end{array}$} \\
\hline$>55$ & $30(71.4 \%)$ & \\
\hline Race & & \\
\hline White & $37(88.1 \%)$ & \\
\hline Not white & $5(11.9 \%)$ & \\
\hline \multicolumn{3}{|r|}{ 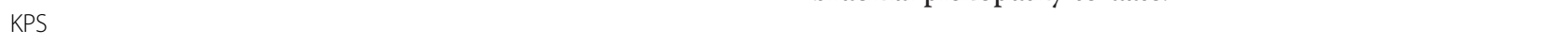 } \\
\hline $90-100$ & $34(81.0 \%)$ & \multirow{22}{*}{$\begin{array}{l}\text { Discussion } \\
\text { To reduce the risk of the potentially debilitating late } \\
\text { effect of brachial plexopathy, BP dose constraints for } \\
\text { head and neck cancer IMRT treatment planning were } \\
\text { adopted at our institution that took precedence over } \\
\text { PTV coverage in the vicinity of the BP. The cohort of } \\
\text { patients with oropharayngeal squamous cell carcinoma } \\
\text { examined here all had lymphadenopathy extending into } \\
\text { levels III or IV of the neck, where there was risk of over- } \\
\text { lap with the brachial plexus. Therefore, they had more } \\
\text { advanced disease and more adverse prognostic features } \\
\text { than seen in recent reports and clinical trials for this dis- } \\
\text { ease [9,12,14]. For example, the rates of local failure and } \\
\text { distant metastases in our updated experience treating } \\
\text { patients with oropharyngeal carcinoma with IMRT were } \\
5.4 \% \text { and } 12.5 \% \text {, compared to } 10 \% \text { and } 29 \% \text { in the subset } \\
\text { reported here [13]. Despite these adverse features, just } \\
\text { one patient experienced an isolated regional recurrence } \\
\text { in proximity of the BP. This patient had a level III } \\
\text { node }>10 \text { cm in maximal diameter, invading into the skin. } \\
\text { At the time of neck dissection for residual tumor, there } \\
\text { was concern of persistent disease at the carotid bulb } \\
\text { which was not amenable to resection. The carotid bulb is } \\
\text { well above the C5 nerve root of the BP. Therefore, it is }\end{array}$} \\
\hline $60-80$ & $8(19.0 \%)$ & \\
\hline Primary site & & \\
\hline Tonsil & $13(31.0 \%)$ & \\
\hline Base of tongue & $29(69.0 \%)$ & \\
\hline Pharyngeal wall & $0(0 \%)$ & \\
\hline Soft palate & $0(0 \%)$ & \\
\hline T stage & & \\
\hline $\mathrm{T} 1$ & $7(16.7 \%)$ & \\
\hline $\mathrm{T} 2$ & $21(50.0 \%)$ & \\
\hline T3 & $6(14.3 \%)$ & \\
\hline T4 & $8(19.0 \%)$ & \\
\hline N stage & & \\
\hline No & $0(0 \%)$ & \\
\hline N1 & $2(4.8 \%)$ & \\
\hline N2 & $34(81.0 \%)$ & \\
\hline N3 & $6(14.3 \%)$ & \\
\hline AJCC Stage & & \\
\hline । & $0(0 \%)$ & \\
\hline$\|$ & $0(0 \%)$ & \\
\hline III & $1(2.4 \%)$ & \\
\hline IV & $41(97.6 \%)$ & \\
\hline Tobacco exposure & & Table 3 Dose volume parameters \\
\hline Never smoked & $8(19.0 \%)$ & Median dose Gy (SD) \\
\hline Former smoker & $26(61.9 \%)$ & PTVBP70 \\
\hline Current smoker & $7(16.7 \%)$ & $66.7(6.4)$ \\
\hline Number of pack years & & Minimum dose \\
\hline Median (range) & $8(0-84)$ & Mean dose \\
\hline Neck dissection before radiation & & $75.2(5.1)$ \\
\hline No & $42(100 \%)$ & Maximum dose \\
\hline Yes & $0(0 \%)$ & Brachial plexus \\
\hline Chemotherapy & $42(100 \%)$ & Maximum dose \\
\hline Concurrent & $38(90.5 \%)$ & $59.1(4.8)$ \\
\hline Cisplatin & $20(47.6 \%)$ & Mean dose \\
\hline
\end{tabular}

Table 2 Patient characteristics (Continued)

overall survival probability was $76 \%$ (95\% CI $0.64-0.90$, Figure 3C). There have been no reported episodes of

(n) 

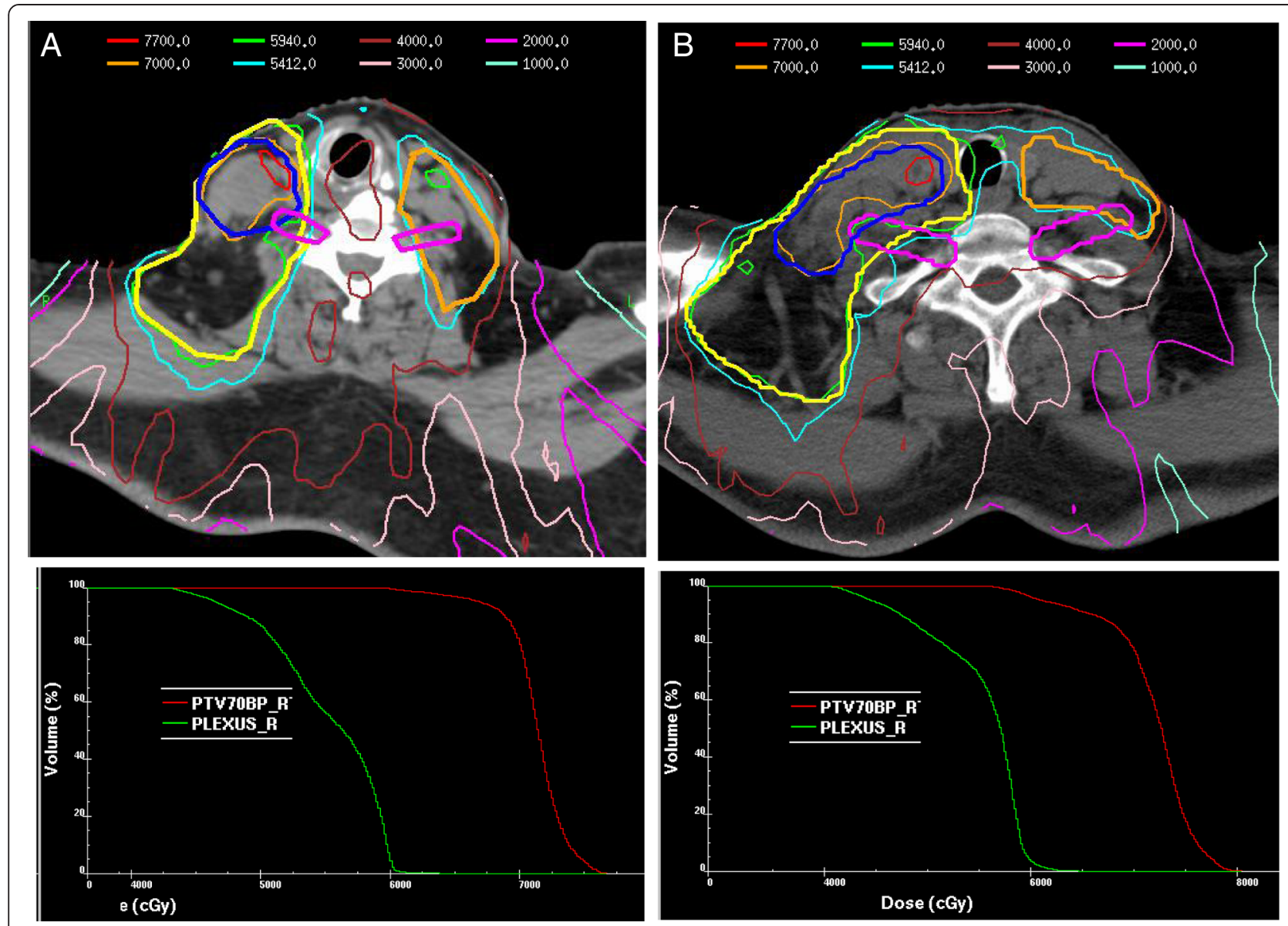

Figure 1 A. and B. CT slices through the low neck at the level of the brachial plexus along with corresponding dose-volume histograms in two representative patients demonstrating constraining of the brachial plexus at the expense of the immediately adjacent gross nodal disease PTV coverage.

unlikely that the $\mathrm{BP}$ constraint had an impact on this treatment outcome, although we cannot exclude that possibility. Ultimately, local control was established with a course of postoperative re-irradiation. Four other patients had regional recurrences on the ipsilateral side of the constrained brachial plexus, but as described above, these tended to be in the high neck and associated with local recurrence at the primary. These patterns of recurrence suggest that tumor biology, rather than brachial plexus dose constraints, were likely responsible for the clinical outcomes and that the treatment approach we adopted, aimed at reducing the long-term risk of brachial plexopathy, may ultimately improve the therapeutic ratio.

Indeed, all 324 patients treated with IMRT for oropharyngeal carcinoma at our institution were spared high doses to the BP during the time period of this study. This is particularly important as recent evidence has emerged, more clearly establishing a dose-response

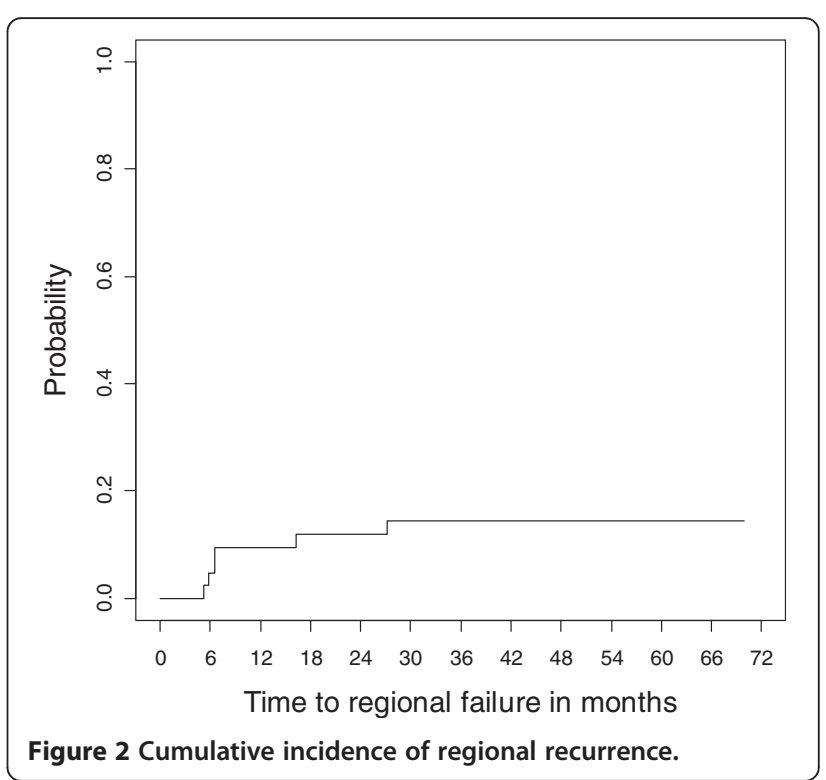



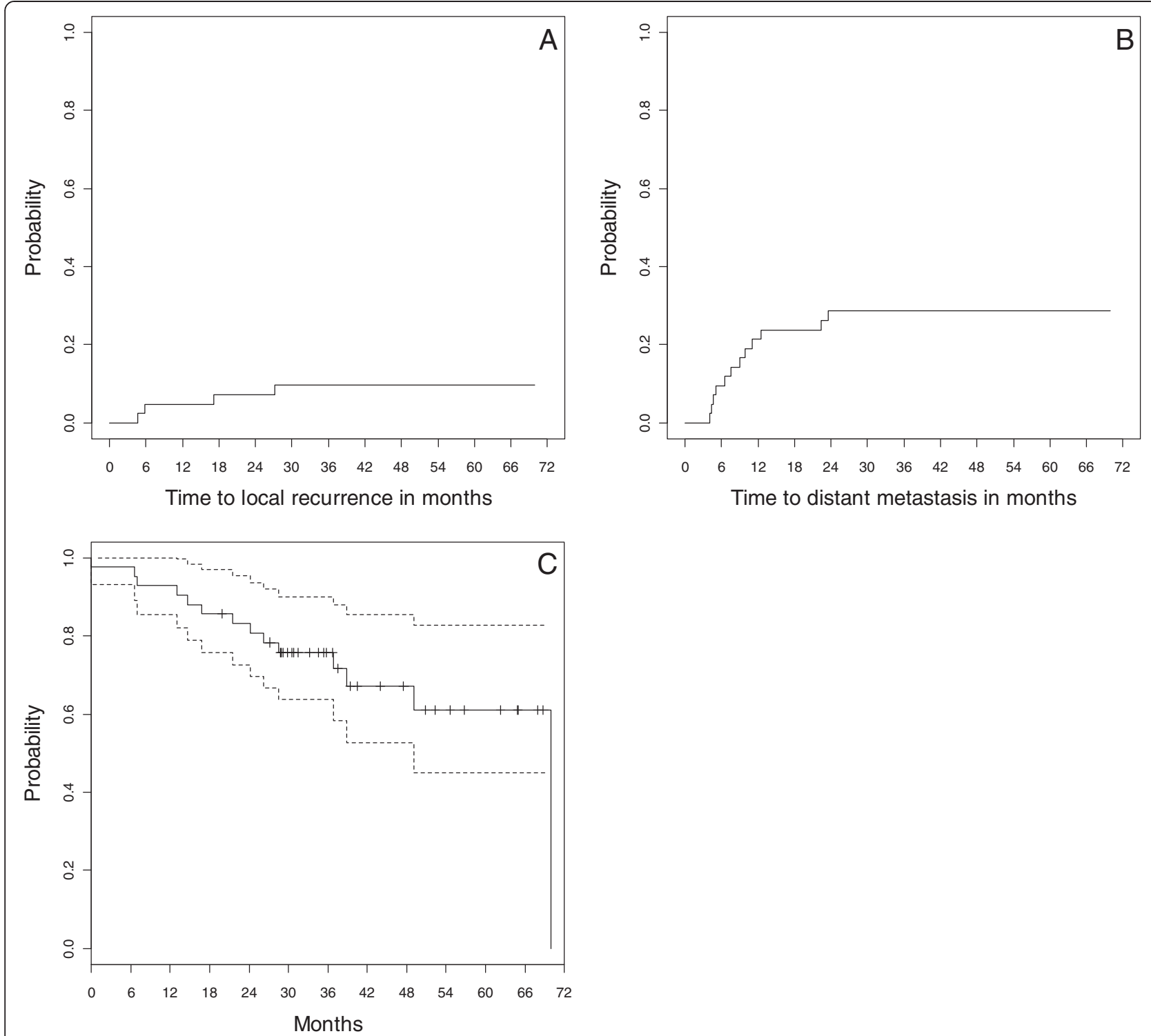

Figure 3 Cumulative incidence of local recurrence (A), distant metastasis (B), and Kaplan-Meier estimates of overall survival (C).

relationship for the development of brachial plexopathy. One report in head and neck cancer patients following RT suggested that the incidence of patient-reported BPassociated neuropathies may be as high as $22 \%$ with long-term follow-up. In that study, Chen et al. demonstrated that radiation maximum dose to the BP was predictive of symptoms. They noted a significantly higher number of patients with symptoms who received doses of $>70$ Gy, suggesting a threshold effect $[2,6]$. Moreover, each Gy increase in maximum dose was associated with 1.39 times greater odds of developing symptoms. In another modern study of lung cancer patients treated with definitive chemoradiation, receipt of a median brachial plexus dose of $>69$ Gy and a maximum dose of $>75$ Gy to $2 \mathrm{~cm}^{3}$ were independent predictors of brachial plexopathy.
The median follow-up time in our study was 35 months; therefore, more time is required to determine the true long-term risk of brachial plexopathy for this cohort of patients where careful attention was paid to limiting the dose to the BP [6]. Moreover, it is possible that a more sensitive screening tool may better identify patients with neuropathic symptoms that could potentially be attributable to RT. To date, however, it is re-assuring that by limiting a small volume of the BP to doses approaching 65-66 Gy, the incidence of brachial plexopathy in our patients, closely followed in a multimodality setting, has been low. This finding is consistent with these studies as well as consensus guidelines $[2,6,15]$.

The clinical decision balancing adequate PTV coverage in the low neck with risk of brachial plexopathy is 
commonly encountered in radiation oncology practice, not unlike other clinical sites such as the central nervous system, where protection of organs at risk such as the optic chiasm or brainstem may impact PTV coverage. Over $10 \%$ of all patients that presented to our institution who underwent definitive radiation for oropharyngeal squamous cell carcinoma had gross disease less than $1 \mathrm{~cm}$ from the BP. In another study, an estimated $20 \%$ of patients with head and neck cancer treated with IMRT had BP maximum point doses of $>66$ Gy [16]. In addition, there is accumulating evidence of a rise in incidence of oropharyngeal cancer in the United States and Western Europe that is associated with an increase in human papillomavirus (HPV)-associated cancers $[17,18]$. HPV-related oropharyngeal carcinomas are associated with younger age at diagnosis [4,14]. Moreover, HPV positivity is an independent predictor of improved overall survival $[14,19]$. Therefore, with patients experiencing longer overall survival rates in this new era of viralinduced carcinoma, efforts to reduce the dose to normal tissue structures, like the brachial plexus, will be of greater importance to limit risks of brachial plexopathy and other late effects of therapy.

One limitation of our study is the lack of tumor HPV status, which has been shown to be associated with improved progression-free and overall survival in oropharyngeal squamous cell carcinoma $[14,20]$. We did, however, have data on tobacco smoking history, which is inversely correlated with HPV status and has also been independently associated with progression-free and overall survival. Due to the small number of recurrences, however, we are unable to draw meaningful conclusions on the impact of smoking status on regional control, let alone control of disease in the vicinity of the BP. We presently continue to apply the same BP constraints for both HPV positive and and HPV negative patients seen in our clinic.

At the Radiation Therapy Oncology Group (RTOG), BP constraints have recently been incorporated into IMRT head and neck cancer protocols (Table 1). Nevertheless, there remains some variation among protocols and controversy about the appropriate treatment approach when disease involves the low neck. For example, on RTOG 0615 for nasopharyngeal carcinoma, the BP dose constraint is a maximum dose $\leq 66$ Gy. On that protocol, the treating radiation oncologist has the option of prescribing an intermediate dose of 63 Gy in the lower neck close to the BP [21]. For RTOG 0912 for anaplastic thyroid carcinoma, BP constraints include a $\mathrm{BP}$ maximum dose $\leq 66$ Gy to a point source at least $0.03 \mathrm{~cm}^{3}$. However, RTOG 0912 specifies that this "suggested dose limit" should not compromise tumor coverage [22]. This is most likely due to the low life expectancy of anaplastic thyroid cancer. For RTOG
1016, the phase 3 trial of radiotherapy plus cetuximab versus chemoradiotherapy in HPV-associated oropharynx cancer, the BP is not defined as a normal tissue/ organ at risk [23]. Notably, the dose specification for low neck nodes on that study is 60 Gy in 30 fractions. Our results may provide some re-assurance to clinicians enrolling patients on these and future studies that BP constraints similar to those used in our study, will not be expected to impact regional control.

It is noteworthy that no patients underwent adaptive radiotherapy with replanning during the course of treatment to account for anatomical changes, such as a reduction in volume of neck lymphadenopathy. It is possible that, in some patients, the dose to the PTV in proximity of the BP was actually greater than what was calculated from the original treatment plan as a result of shrinkage of gross disease away from the BP and into the higher-dose region of the PTV. In addition, all patients in this study received concurrent chemoradiation, the majority of which was platinum based. Cisplatin has been perhaps the most widely used chemotherapeutic agent in combination with radiation. The biological basis of radiation sensitization from platinum is evolving but the most widely believed explanation is through inhibition of sublethal damage repair [24]. We have previously reported inferior locoregional control with concurrent cetuximab-based chemoradiation compared with cisplatin [25]. We would therefore caution that our data may not imply the safety of any compromise of PTV coverage to meet BP dose constraints in patients not receiving concurrent cisplatin-based chemotherapy.

\section{Conclusion}

In conclusion, in the context of combined-modality therapy, including ND as salvage, regional control did not appear to be compromised by constraining the dose to the BP. We expect that attention to these normal tissue dose-volume parameters will ultimately reduce the risk of brachial plexopathy long-term. Our findings suggest that when multimodality therapy is utilized to treat OPC, BP constraints resembling those adopted at our institution are safe. Furthermore, our study provides data to justify constraining the $\mathrm{BP}$ in present and future IMRT protocols for OPC. Close attention to sites of recurrence are warranted on these prospective studies, however, to confirm the findings reported here.

Competing interests

The authors declare that they have no competing interest.

\section{Authors' contributions}

$\mathrm{NL}, \mathrm{RM}, \mathrm{PD}$, and $\mathrm{BL}$ conceived of the study and participated in its design and coordination. RM, BL, PD, NR, JS, SB, AG, SR, SW, and NL accumulated and analyzed data. ZZ performed statistical analysis. SB, BL, and RM carried out the dosimetric analysis. RM and NL drafted the manuscript. All authors read and approved the final manuscript. 


\section{Author details}

'Department of Radiation Oncology, Mayo Clinic, 200 First Street SW, Rochester, Minnesota 55905, USA. ²Department of Radiation Oncology, Memorial Sloan-Kettering Cancer Center, New York, USA. ${ }^{3}$ Department of Medical Physics, Memorial Sloan-Kettering Cancer Center, New York, USA. ${ }^{4}$ Department of Epidemiology and Biostatistics, Memorial Sloan-Kettering Cancer Center, New York, USA

Received: 11 December 2012 Accepted: 17 March 2013 Published: 9 July 2013

\section{References}

1. Schierle C, Winograd JM: Radiation-induced brachial plexopathy: review. Complication without a cure. J Reconstr Microsurg 2004, 20:149-152.

2. Amini A, Yang J, Williamson R, McBurney ML, Erasmus J Jr, Allen PK, Karhade M, Komaki R, Liao Z, Gomez D, Cox J, Dong L, Welsh J: Dose constraints to prevent radiation-induced brachial plexopathy in patients treated for lung cancer. Int J Radiat Oncol Biol Phys 2012, 82:e391-e398.

3. Kori SH, Foley KM, Posner JB: Brachial plexus lesions in patients with cancer: 100 cases. Neurology 1981, 31:45-50.

4. Powell S, Cooke J, Parsons C: Radiation-induced brachial plexus injury: follow-up of two different fractionation schedules. Radiother Oncol 1990, 18:213-220

5. Svensson $H$, Westling P, Larsson LG: Radiation-induced lesions of the brachial plexus correlated to the dose-time-fraction schedule. Acta Radiol Ther Phys Biol 1975, 14:228-238.

6. Chen AM, Hall WH, Li J, Beckett L, Farwell DG, Lau DH, Purdy JA: Brachial plexus-associated neuropathy after high-dose radiation therapy for head-and-neck cancer. Int J Radiat Oncol Biol Phys 2012, 84:165-169.

7. De Arruda FF, Puri DR, Zhung J, Narayana A, Wolden S, Hunt M, Stambuk H, Pfister D, Kraus D, Shaha A, Shah J, Lee NY: Intensity-modulated radiation therapy for the treatment of oropharyngeal carcinoma: the memorial sloan-kettering cancer center experience. Int J Radiat Oncol Biol Phys 2006, 64:363-373.

8. Lee N, Mechalakos J, Puri DR, Hunt M: Choosing an intensity-modulated radiation therapy technique in the treatment of head-and-neck cancer. Int J Radiat Oncol Biol Phys 2007, 68:1299-1309.

9. Lok BH, Setton J, Caria N, Romanyshyn J, Wolden SL, Zelefsky MJ, Park J, Rowan N, Sherman EJ, Fury MG, Ho A, Pfister DG, Wong RJ, Shah JP, Kraus DH, Zhang Z, Schupak KD, Gelblum DY, Rao SD, Lee NY: Intensitymodulated radiation therapy in oropharyngeal carcinoma: effect of tumor volume on clinical outcomes. Int J Radiat Oncol Biol Phys 2012, 82:1851-1857.

10. Gray R: A class of K-sample tests for comparing the cumulative incidence of a competing risk. Ann Stat 1988, 16:1141-1154.

11. Kaplan E, Meier P: Nonparametric-estimation from incomplete observations. J Am Stat Assoc 1958, 53:457-481.

12. Denis $F$, Garaud $P$, Bardet $E$, Alfonsi $M$, Sire $C$, Germain $T$, Bergerot $P$, Rhein $B$, Tortochaux J, Calais G: Final results of the 94-01 french head and neck oncology and radiotherapy group randomized trial comparing radiotherapy alone with concomitant radiochemotherapy in advancedstage oropharynx carcinoma. J Clin Oncol 2004, 22:69-76.

13. Setton J, Caria N, Romanyshyn J, Koutcher L, Wolden SL, Zelefsky MJ, Rowan $\mathrm{N}$, Sherman EJ, Fury MG, Pfister DG, Wong RJ, Shah JP, Kraus DH, Shi W, Zhang Z, Schupak KD, Gelblum DY, Rao SD, Lee NY: Intensity-modulated radiotherapy in the treatment of oropharyngeal cancer: an update of the memorial sloan-kettering cancer center experience. Int J Radiat Oncol Biol Phys 2012, 82:291-298.

14. Ang KK, Harris J, Wheeler R, Weber R, Rosenthal DI, Nguyen-Tan PF, Westra WH, Chung CH, Jordan RC, Lu C, Kim H, Axelrod R, Silverman CC, Redmond KP, Gillison ML: Human papillomavirus and survival of patients with oropharyngeal cancer. N Eng J Med 2010, 363:24-35.

15. Emami B, Lyman J, Brown A, Coia L, Goitein M, Munzenrider JE, Shank B, Solin $L$, Wesson M: Tolerance of normal tissue to therapeutic irradiation. Int J Radiat Oncol Biol Phys 1991, 21:109-122.

16. Truong MT, Romesser PB, Qureshi MM, Kovalchuk N, Orlina L, Willins J: Radiation dose to the brachial plexus in head-and-neck intensitymodulated radiation therapy and its relationship to tumor and nodal stage. Int J Radiat Oncol Biol Phys 2012, 84:158-164.
17. Chaturvedi AK, Engels EA, Anderson WF, Gillison ML: Incidence trends for human papillomavirus-related and -unrelated oral squamous cell carcinomas in the united states. J Clin Oncol 2008, 26:612-619.

18. Nasman A, Attner P, Hammarstedt L, Du J, Eriksson M, Giraud G, AhrlundRichter S, Marklund L, Romanitan M, Lindquist D, Ramqvist T, Lindholm J, Sparen P, Ye W, Dahlstrand H, Munck-Wikland E, Dalianis T: Incidence of human papillomavirus (HPV) positive tonsillar carcinoma in stockholm, sweden: an epidemic of viral-induced carcinoma? International journal of cancer. Journal international du cancer 2009, 125:362-366.

19. Fakhry C, Westra WH, Li S, Cmelak A, Ridge JA, Pinto H, Forastiere A, Gillison ML: Improved survival of patients with human papillomavirus-positive head and neck squamous cell carcinoma in a prospective clinical trial. J Natl Cancer Inst 2008, 100:261-269.

20. Kong FM, Ritter T, Quint DJ, Senan S, Gaspar LE, Komaki RU, Hurkmans CW Timmerman R, Bezjak A, Bradley JD, Movsas B, Marsh L, Okunieff P, Choy H, Curran WJ Jr: Consideration of dose limits for organs at risk of thoracic radiotherapy: atlas for lung, proximal bronchial tree, esophagus, spinal cord, ribs, and brachial plexus. Int J Radiat Oncol Biol Phys 2011, 81:1442-1457.

21. Radiation Therapy Oncology Group (RTOG) 0615: A phase // study of concurrent chemoradiotherapy using three-dimensional conformal radiotherapy (3D-CRT) or intensity-modulated radiation therapy (IMRT) + bevacizub (BV) for locally or regionally advanced nasopharyngeal cancer. 2011 [http://www.rtog.org/ClinicalTrials/ProtocolTable/StudyDetails.aspx? study=0615. Accessed Nov. 11, 2011].

22. Radiation Therapy Oncology Group (RTOG) 0912: A randomized phase II study of concurrent intensity modulated radiation therapy (IMRT), paclitaxel and pazopanib (NSC 737754)/placebo, for the treatment of anaplastic thyroid cancer. 2011. http://www.rtog.org/ClinicalTrials/ProtocolTable/StudyDetails. aspx?study=0912. Accessed Nov. 11, 2011.

23. Radiation Therapy Oncology Group (RTOG) 1016: 2011. http://www.rtog.org/ ClinicalTrials/ProtocolTable/StudyDetails.aspx?study=1016. Accessed Nov. 11, 2011.

24. Wilson GD, Bentzen SM, Harari PM: Biologic basis for combining drugs with radiation. Semin Radiat Oncol 2006, 16:2-9.

25. Koutcher L, Sherman E, Fury M, Wolden S, Zhang Z, Mo Q, Stewart L, Schupak K, Gelblum D, Wong R, Kraus D, Shah J, Zelefsky M, Pfister D, Lee $\mathrm{N}$ : Concurrent cisplatin and radiation versus cetuximab and radiation for locally advanced head-and-neck cancer. Int J Radiat Oncol Biol Phys 2011, 81:915-922.

\section{doi:10.1186/1748-717X-8-173}

Cite this article as: Robert et al:: Constraining the brachial plexus does not compromise regional control in oropharyngeal carcinoma. Radiation Oncology 2013 8:173.

\section{Submit your next manuscript to BioMed Central and take full advantage of:}

- Convenient online submission

- Thorough peer review

- No space constraints or color figure charges

- Immediate publication on acceptance

- Inclusion in PubMed, CAS, Scopus and Google Scholar

- Research which is freely available for redistribution 